\title{
Networking
}

\section{Using teleconferencing to enable general practitioner participation in focus groups}

Helen Tolhurst School of Medical Practice and Population Health, Faculty of Health, University of Newcastle, Australia and Sarah Dean Faculty of Medicine, University of Sydney, Australia

\begin{abstract}
Focus groups are used increasingly in general practice research, especially where a qualitative method is required to answer exploratory questions. Recently teleconferencing has been used to conduct focus groups in research on rural general practitioners, where distance makes face-to-face focus groups difficult and where anonymity of participants is important. This paper discusses advantages and disadvantages of using teleconferencing as a means of undertaking focus groups and provides examples of research where this has been used. We conclude that focus groups, conducted using teleconferencing, are an appropriate method in research on general practitioners, and can be particularly useful, when conducting research in rural and remote areas, and when anonymity of participants is desirable.
\end{abstract}

Key words: focus group; general practice; research; rural; teleconference

\section{Introduction}

Focus groups have become a common method in general practice research (Cho et al., 1995; Schattner et al., 1993). Research has shown general practitioners often mention time constraints as a barrier to their participation in research studies (Gray et al., 2001; Jowett et al., 2000). As the participation in face-to-face focus groups is a time consuming activity for participants it would be expected that minimizing the time commitment expected of participants would assist in overcoming this barrier. This is particularly the case when the research is being conducted in rural and remote areas where attendance at face-to-face focus groups involves travel to distant locations. A Norwegian study showed that female general practitioners (GPs) regarded their family commitments as a barrier to participation in research (Forde and Evenson, 1991). Teleconference focus groups are

Address for correspondence: Dr Helen Tolhurst, Rural Research Fellow, Discipline of General Practice (Newbolds), School of Medical Practice and Population Health, Faculty of Health, University of Newcastle, University Drive, Callaghan, NSW 2308, Australia. Email: helen.tolhurst@newcastle.edu.au a method which can provide GPs with the opportunity to participate without the need to travel to a particular location and which could potentially facilitate female GPs' participation in some research while also meeting their family commitments.

Recently the focus group method has been adapted to use teleconferencing for health care research (Appleby et al., 1999; Tolhurst et al., 1997; Tolhurst et al., 1999; Tudiver et al., 2001; White et al., 1994; White and Thomson, 1995). We discuss the use of teleconference focus groups for research on GPs.

\section{Teleconference focus groups as research methodology}

Teleconferencing is a system that joins three or more participants in different locations through a telephone system (Kuramoto and Dean, 1993). Telephone groups have been used for group support (Macintosh, 1981; Wildsoet et al., 1996), education (Macintosh 1981; Wildsoet et al., 1996), group interviews, organizational tasks, contacts before and after face-to-face meetings (Schopler 
et al., 1998), and in market research (Garigliano, 1998). Teleconference focus groups are similar to face-to-face focus groups, but there are specific advantages and disadvantages of using them. Participants are recruited in the same way as they would be for face-to-face focus groups either by letter or telephone, and the focus groups are conducted in much the same way in terms of using an interview schedule if they are semistructured, and of having a facilitator to conduct the focus group. Many issues pertaining to audioconferencing are equally applicable to videoconferencing.

\section{Guidelines for the use of focus groups as a health research method}

The guidelines for the use of teleconference focus groups, are similar to those for face-to-face focus groups, in relation to size, structure, length of time, homogeneity and confidentiality.

Guidelines for the design of focus groups for general practice research, which can be applied to teleconference focus groups include:

- Structured with a defined set of focus group questions (Morgan, 1992).

- Less than one and a half hours long because of problems with fatigue, loss of interest, poor validity (Cho et al., 1995).

- The group should be homogenous in terms of at least one research factor (Cho et al., 1995) with homogenous composition for more effective communication, and heterogeneous composition for generating richer, more varied data. Examples of research factors for which focus groups may be homogeneous are gender, age group, and geographical area.

- Participants must give informed consent and be aware before the session begins that a videotape or audiotape recording will be made. Individual contributions must remain confidential and anonymous (Schattner et al., 1993).

- Members should be asked to ensure the privacy of other's communications as in face-to-face focus groups but may need to be particularly aware of this if on the telephone in the home (Appleby et al., 1999).

- Group structure and size are two important factors (Morgan, 1992). The usual size of focus groups is six to 10 participants (Cho et al.,
1995; Schattner et al., 1993). Small groups, which generate more intense and detailed discussions are recommended for research which delves deeply into detailed experiences and feelings of individuals. Larger groups, which produce a brief, steady flow of information, are recommended for research, which requires generation of a number of ideas. (Morgan, 1992).

\section{Advantages of teleconferencing for focus groups}

Cost effective in terms of time and travel:

- Teleconferencing enables practitioners to participate in research focus groups when time and financial costs make this difficult. The time commitment and inconvenience of travel have been identified as barriers to participation of GPs in focus groups (Schattner et al., 1993) Inconvenience can be minimized by teleconferencing. Examples of research where teleconferencing was used to facilitate the recruitment of GPs, located in rural and remote areas, are studies conducted by Tudiver et al. in Canada (2001) and Tolhurst et al. in Australia (1997, 1999).

In our studies of female rural GPs (Tolhurst et al., 1997) and violence against rural GPs (Tolhurst et al., 1999), GPs from remote areas of Australia, over $1000 \mathrm{kms}$ apart, were able to participate, without the cost and time commitment that would have been required for a faceto-face focus group.

Increased level of anonymity when discussing sensitive issues:

- Conducting groups by teleconference has anonymity and facilitates discussion of sensitive issues (Schopler et al., 1998; White and Thomson, 1995), an example being a study conducted by White et al. in New Zealand on sexual relationships between doctors and patients (White etal., 1994). This study used teleconferencing to provide anonymity to the participants. The researchers explained, 'focus groups are usually less suitable for exploring highly sensitive or personally threatening issues, personal interviews or anonymous mailings being preferred' (White et al., 1994: 391). The 
focus group adaptation in this study used the strengths of the focus group method and maintained anonymity. The participants in this study were able to freely disclose personal experiences, beliefs, and values within the group without the threat of being identified.

Overcoming conflicting responsibilities of participants:

- Teleconferencing overcomes problems with participants' conflicting responsibilities, such as family responsibilities. For example, in our study of female rural GPs the use of teleconferencing enabled participants, with child care responsibilities, to remain at home, while participating in the focus group (Tolhurst, 1997).

\section{Limitations of the use of teleconferencing for focus groups}

Lack of nonverbal cues:

- A constraint in using teleconferencing is the lack of nonverbal cues (White and Thomson, 1995), which may be important in the direction, which the discussion takes, and in the level of group participation. For example, during a teleconference the facilitator is unable to observe nonverbal signs of participants' agreement or dissatisfaction in relation to other participants' contribution, or distress when sensitive issues are being discussed.

The need for the appropriate technology:

- Most potential participants have access to a telephone and most telephone service providers can provide teleconferencing facilities. However technological support is critical to the implementation and maintenance of group activity (Schopler et al., 1998).

Possible bias in sampling:

- It is possible that GPs who do not have experience in the use of teleconferencing might be uncomfortable with this method and less likely to participate in teleconference focus groups although no research has been undertaken exploring this issue.

\section{Discussion}

These examples show that teleconferencing for focus groups is a useful method for research on general practitioners. The guidelines outlined above for face-to-face focus groups can easily be adhered to when conducting groups by teleconference. Teleconferencing can be cost effective in general practice research. Its use has the potential to encourage the participation of GPs who otherwise may not participate because of geographical location or commitments at home, by minimizing the time commitment of the GPs, and providing a high degree of anonymity to participants, when discussing sensitive issues.

The use of teleconferencing in general practice research demonstrates how new technology incorporated with older research methodologies creates new research methods.

\section{References}

Appleby, N.J., Dunt, D., Southern, D.M. and Young, D. 1999: General practice integration in Australia. Primary health services provider and consumer perceptions of barriers and solutions. Australian Family Physician 28(8), 858-63.

Cho, T.K., Davis, A., Sullivan, S. and Fisher, J. 1995: A review of five existing guidelines for planning focus groups in GP research. Australian Family Physician 24(2), 184-86.

Clapper, D.L. and Mussey, A.P. 1996: Electronic focus groups: a framework for explanation. Information and Management 30, 43-50.

Forde, R. and Evensen, A.R. 1991. Research activities and research interest among female general practitioners. Why so few when so many are interested? Tidsskrift for Den Norske Laegeforening 111(9), 1136-38.

Garigliano, J. 1998: The next best thing to being there. Folio: the Magazine for Magazine Management 27(7), 21.

Gray, R.W., Woodward, N.J. and Carter, Y.H. 2001. Barriers to the development of collaborative research in general practice: a qualitative study. British Journal of General Practice 51(464), 221-22.

Jowett, S.M., Macleod, J., Wilson, S. and Hobbs, F.D. 2000. Research in primary care: extent of involvement and perceived determinants among practitioners from one English region. British Journal of General Practice 50(454): 387-89.

Krueger, R.A. 1988: Focus Groups. London: Sage, 41-8.

Kuramoto, A.M. and Dean, J.L. 1993: Audiographics teleconferencing: a method of distance learning. Journal of Nursing Staff Development 13(1), 13-17.

MacIntosh, J.A. 1993: Focus groups in distance nursing education. Journal of Advanced Nursing 18(12), 1981-85. 
Morgan, D.L. 1992: Designing focus group research. In Stewart, M., Tudiver, F., Bass, M.J., Dunn, E.V. and Norton, P.G., editors, Tools for Primary Care Research. London: Sage, 180-93.

Schattner, P., Schmerling, A. and Murphy, B. 1993: Focus groups: a useful research method in general practice. Medical Journal of Australia 158, 623-25.

Schopler, J.H., Abell, M.D. and Galinsky, M.J. 1998: Technology-based groups: a review and conceptual framework for practice. Social Work 43(3): 254-68.

Tolhurst, H., Bell, P., Baker, L., Talbot, J. and Cleasby, L. 1997: Educational and Support Needs of Female Rural General Practitioners. Discipline of General Practice. Faculty of Medicine and Health Sciences, University of Newcastle, Newcastle, Australia.

Tolhurst, H., Talbot, J., Bell, P., Baker, L., Murray, G., McMillan, J., Sutton, A., Treloar, C. and Harris, G. 1999: After Hours Medical Care and Personal Safety Needs of Rural General Practitioners: Final report to the General Practice
Evaluation Program. Canberra: Department of Health and Aged Care, ACT.

Tudiver, F., Brown, J., Medved, W., Herbert, C., Guibert, P., Haggerty, J., Goel, V., Smith, J., Obeirne, M., Katz, A., Molin, P., Ciampi, A. and Williams, J.I. 2001: Making decisions about cancer screening when the guidelines are unclear or conflicting. Journal of Family Practice 50(8), 674-82.

Wildsoet, C., Wood, J. and Parke, J. 1996: Audio-teleconferencing as a medium for distance learning: an application for continuing education in optometry. Australian Journal of Rural Health 4(1), 18-27.

White, G.E., Coverdale, J.A., Thomson, A.N. 1994: Can one be a good doctor and have a sexual relationship with one's patient? Family Practice 11(4), 389-93.

White, G.E. and Thomson, A.N. 1995: Anonymized focus groups as a research tool for health professionals. Qualitative Health Research 5(2), 256-62. 